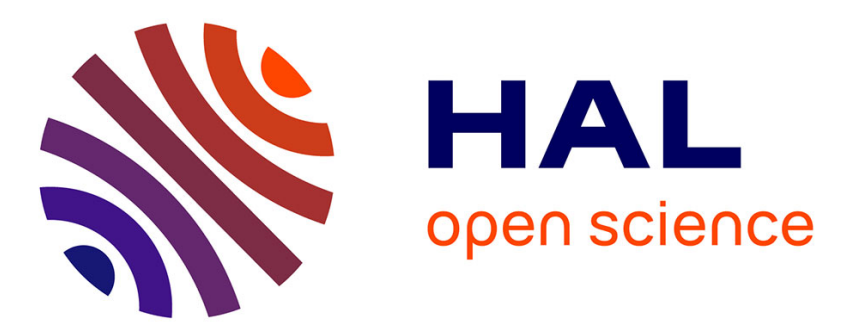

\title{
Structural study and ferroelectricity of epitaxial BaTiO3 films on silicon grown by molecular beam epitaxy
}

\author{
Lucie Mazet, Romain Bachelet, Lamis Louahadj, David Albertini, Brice \\ Gautier, Robin Cours, Sylvie Schamm-Chardon, Guillaume Saint-Girons, \\ Catherine Dubourdieu
}

\section{To cite this version:}

Lucie Mazet, Romain Bachelet, Lamis Louahadj, David Albertini, Brice Gautier, et al.. Structural study and ferroelectricity of epitaxial BaTiO3 films on silicon grown by molecular beam epitaxy. Journal of Applied Physics, 2014, 116 (21), pp.214102. 10.1063/1.4902165 . hal-01489886

\section{HAL Id: hal-01489886 https://hal.science/hal-01489886}

Submitted on 1 Mar 2018

HAL is a multi-disciplinary open access archive for the deposit and dissemination of scientific research documents, whether they are published or not. The documents may come from teaching and research institutions in France or abroad, or from public or private research centers.
L'archive ouverte pluridisciplinaire HAL, est destinée au dépôt et à la diffusion de documents scientifiques de niveau recherche, publiés ou non, émanant des établissements d'enseignement et de recherche français ou étrangers, des laboratoires publics ou privés. 


\section{Structural study and ferroelectricity of epitaxial $\mathrm{BaTiO}_{3}$ films on silicon grown by molecular beam epitaxy}

L. Mazet, R. Bachelet, L. Louahadj, D. Albertini, B. Gautier, R. Cours, S. Schamm-Chardon, G. Saint-Girons, and C. Dubourdieu

Citation: Journal of Applied Physics 116, 214102 (2014); doi: 10.1063/1.4902165

View online: https://doi.org/10.1063/1.4902165

View Table of Contents: http://aip.scitation.org/toc/jap/116/21

Published by the American Institute of Physics

\section{Articles you may be interested in}

Strong oxygen pressure dependence of ferroelectricity in $\mathrm{BaTiO}_{3} / \mathrm{SrRuO}_{3} / \mathrm{SrTiO}_{3}$ epitaxial heterostructures Journal of Applied Physics 114, 124101 (2013); 10.1063/1.4821643

High ferroelectric polarization in c-oriented $\mathrm{BaTiO}_{3}$ epitaxial thin films on $\mathrm{SrTiO}_{3} / \mathrm{Si}(001)$

Applied Physics Letters 109, 122903 (2016); 10.1063/1.4962836

Epitaxial c-axis oriented $\mathrm{BaTiO}_{3}$ thin films on $\mathrm{SrTiO}_{3}$-buffered $\mathrm{Si}(001)$ by atomic layer deposition

Applied Physics Letters 104, 082910 (2014); 10.1063/1.4867469

$C$-axis oriented epitaxial $\mathrm{BaTi}_{3}$ films on $(001) \mathrm{Si}$

Journal of Applied Physics 100, 024108 (2006); 10.1063/1.2203208

Ferroelectric thin films: Review of materials, properties, and applications

Journal of Applied Physics 100, 051606 (2006); 10.1063/1.2336999

Critical thickness of ultrathin ferroelectric $\mathrm{BaTiO}_{3}$ films

Applied Physics Letters 86, 102907 (2005); 10.1063/1.1880443

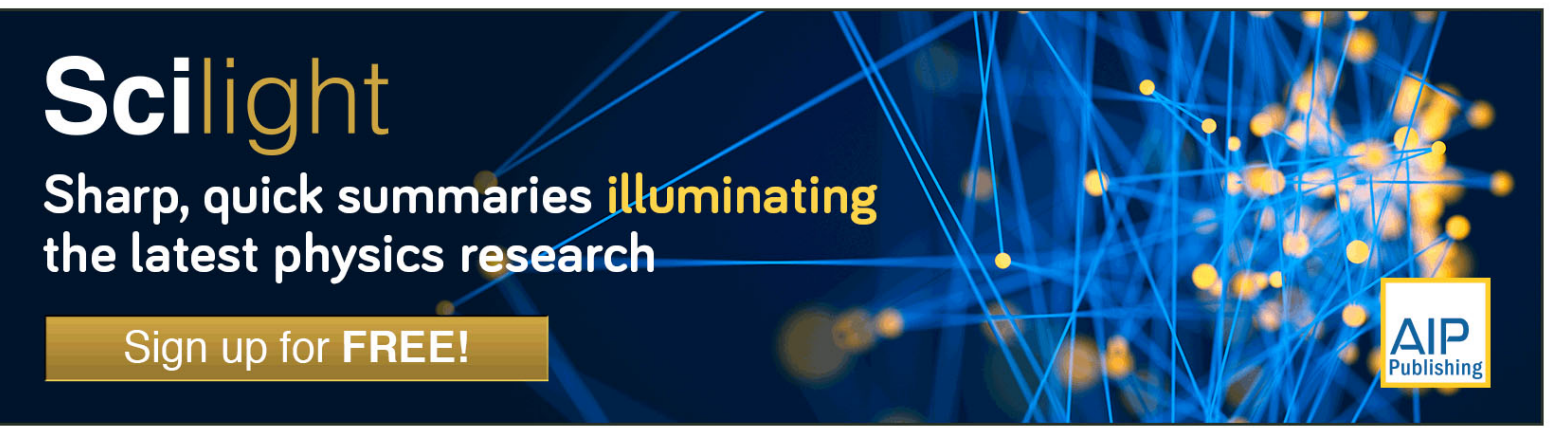




\title{
Structural study and ferroelectricity of epitaxial $\mathrm{BaTiO}_{3}$ films on silicon grown by molecular beam epitaxy
}

\author{
L. Mazet, ${ }^{1}$ R. Bachelet, ${ }^{1}$ L. Louahadj, ${ }^{2}$ D. Albertini, ${ }^{3}$ B. Gautier, ${ }^{3}$ R. Cours, ${ }^{4}$ \\ S. Schamm-Chardon, ${ }^{4}$ G. Saint-Girons, ${ }^{1}$ and C. Dubourdieu ${ }^{1}$ \\ ${ }^{1}$ Institut des Nanotechnologies de Lyon (INL), UMR CNRS 5270, Ecole Centrale de Lyon, \\ 36 avenue Guy de Collongue, 69134 Ecully, France \\ ${ }^{2}$ RIBER SA, 31 rue Casimir Périer, 95870 Bezons, France \\ ${ }^{3}$ Institut des Nanotechnologies de Lyon (INL), UMR CNRS 5270, INSA de Lyon, 7 Avenue Jean Capelle, \\ 69621 Villeurbanne, France \\ ${ }^{4}$ CEMES-CNRS, Université de Toulouse, 29 rue Jeanne Marvig, 31055 Toulouse, France
}

(Received 15 September 2014; accepted 8 November 2014; published online 2 December 2014)

\begin{abstract}
Integration of epitaxial complex ferroelectric oxides such as $\mathrm{BaTiO}_{3}$ on semiconductor substrates depends on the ability to finely control their structure and properties, which are strongly correlated. The epitaxial growth of thin $\mathrm{BaTiO}_{3}$ films with high interfacial quality still remains scarcely investigated on semiconductors; a systematic investigation of processing conditions is missing although they determine the cationic composition, the oxygen content, and the microstructure, which, in turn, play a major role on the ferroelectric properties. We report here the study of various relevant deposition parameters in molecular beam epitaxy for the growth of epitaxial tetragonal $\mathrm{BaTiO}_{3}$ thin films on silicon substrates. The films were grown using a 4 nm-thick epitaxial $\mathrm{SrTiO}_{3}$ buffer layer. We show that the tetragonality of the $\mathrm{BaTiO}_{3}$ films, the crystalline domain orientations, and $\mathrm{SiO}_{2}$ interfacial layer regrowth strongly depend on the oxygen partial pressure and temperature during the growth and on the post-deposition anneal. The ferroelectricity of the films, probed using piezoresponse force microscopy, is obtained in controlled temperature and oxygen pressure conditions with a polarization perpendicular to the surface. (C) 2014 AIP Publishing LLC.
\end{abstract}

[http://dx.doi.org/10.1063/1.4902165]

\section{INTRODUCTION}

Integration of epitaxial complex ferroelectric oxides such as $\mathrm{BaTiO}_{3}$ on semiconductor substrates has been proposed for the fabrication of new silicon-based electronic and photonic devices. ${ }^{1-4}$ Since the first epitaxial growth of the perovskite $\mathrm{SrTiO}_{3}$ on silicon by molecular beam epitaxy (MBE) ${ }^{5}$ various studies were carried out to integrate functional oxides on semiconductor platforms. ${ }^{5-17}$ Among the functionalities, ferroelectricity is one of the most appealing, in particular, for applications such as ferroelectric fieldeffect transistors (FETs) for steep subthreshold slope transistors. ${ }^{1,2}$ Such devices would enable low-voltage operation of logic devices and therefore reduction of power consumption. $\mathrm{BaTiO}_{3}$ is an attractive candidate for applications such as negative-capacitance field-effect devices since it has a moderate Curie temperature. ${ }^{1,18,19}$ It is a well-known perovskite largely studied for its dielectric, piezoelectric, and ferroelectric properties. For the targeted applications, it is desirable that $\mathrm{BaTiO}_{3}$ be ferroelectric with a polarization pointing outof-plane. However, the growth of tetragonal $c$-axis oriented $\mathrm{BaTiO}_{3}$ (the $c$-axis is perpendicular to the substrate plane) tends to be impeded by the large lattice mismatch $(\backsim 4.4 \%)$ and thermal mismatch between $\mathrm{BaTiO}_{3}$ and silicon. Due to the difference in the thermal expansion coefficients, the deposited film experiences a tensile bi-axial stress during the cooling down period, which favors the in-plane orientation of the long axis of the cell. Moreover, the out-of-plane polarization is not favored because of the depolarization field that arises due to incomplete charge screening at the interface with the semiconductor or insulating buffer. Tetragonal $c$-axis films have been obtained using $\mathrm{Ba}(\mathrm{Sr}) \mathrm{TiO}_{3}$ (Ref. 7) or $\mathrm{SrTiO}_{3}$ (Refs. 3, 4, 8, 11, 13, and 14) as a buffer layer. The $\mathrm{SrTiO}_{3} / \mathrm{Si}$ system has been widely studied ${ }^{20-23}$ and substrate's like quality can be obtained. Reversible switching of the ferroelectric polarization of $\mathrm{BaTiO}_{3}$ thin films on $\mathrm{SrTiO}_{3}$-buffered silicon with no bottom electrode has been reported recently by few groups. ${ }^{4,13,14}$ However, a systematic study of relevant molecular beam epitaxy parameters on the growth of $\mathrm{BaTiO}_{3}$ on silicon is missing, although the resulting crystalline orientation and microstructure strongly depend on the processing conditions and strongly impact the ferroelectric properties.

Among the growth parameters, oxygen pressure has been shown to have a significant influence on the structure and properties of $\mathrm{BaTiO}_{3}$ films. Zhao et al. observed a dependence of the crystallographic orientation on the oxygen pressure in the range of $1.5 \times 10^{-6}$ to $10^{-1}$ Torr for films grown on $\mathrm{SrTiO}_{3}$ by laser MBE. ${ }^{24} \mathrm{Zhu}$ et al. ${ }^{25}$ observed a change in the type of predominant defects in laser-MBE grown $\mathrm{BaTiO}_{3}$ on $\mathrm{SrTiO}_{3}$ by varying the oxygen pressure in the range of $1.5 \times 10^{-7}$ to $1.5 \times 10^{-4}$ Torr. Rutkowski et al. observed a dependence with $\mathrm{P}\left(\mathrm{O}_{2}\right)$ of $(\mathrm{Ba}, \mathrm{Sr}) \mathrm{TiO}_{3}$ film composition grown by $\mathrm{MBE}$ on $\mathrm{SrTiO}_{3}{ }^{26}$ There are also numerous studies on the oxygen dependence of $\mathrm{BaTiO}_{3}$ microstructure for films grown by sputtering or conventional pulsed laser deposition (PLD), either on $\mathrm{SrTiO}_{3}$ or $\mathrm{MgO}$ substrates. $^{27-36}$ In these works, it has been reported that by 
increasing the oxygen pressure, the out-of-plane lattice parameter decreases and that the films are in-plane oriented. This phenomenon was reported for $\mathrm{Ba}_{\mathrm{x}} \mathrm{Sr}_{1-\mathrm{x}} \mathrm{TiO}_{3}$ as well. ${ }^{37,38}$ The increase of the surface roughness with oxygen pressure was also observed. ${ }^{27,28,35,36}$ Temperature is another crucial growth parameter. For the $\mathrm{MBE}$ of $\mathrm{BaTiO}_{3}$ on silicon, the optimal window has to be determined; indeed, a compromise has to be found between crystallization of the perovskite phase and interdiffusion at the silicon interface with the $\mathrm{SrTiO}_{3}$ template. As already pointed out, a systematic study of relevant molecular beam epitaxy parameters on the growth of $\mathrm{BaTiO}_{3}$ on silicon is missing.

Here, we report the investigation of molecular beam epitaxy processing conditions for the epitaxial growth of $\mathrm{BaTiO}_{3}$ on $\mathrm{SrTiO}_{3}$-buffered silicon. The evolution of the crystalline structure of the films with critical deposition parameters such as temperature, oxygen pressure, or cooling conditions is studied. We discuss the conditions that favor flat surfaces and mainly $c$-axis oriented films. Ferroelectricity is evidenced by piezoresponse force microscopy (PFM) in specific growth conditions, with a polar axis pointing perpendicular to the substrate's plane.

\section{EXPERIMENTAL}

The epitaxial stacks were grown by $\mathrm{MBE}$ using $\mathrm{Sr}, \mathrm{Ba}$ effusion cells. The flux of each cell was carefully measured and adjusted prior to the growth. For $\mathrm{Ti}$, we used either an e-beam gun or an effusion cell. The $4 \mathrm{~nm}$-thick epitaxial $\mathrm{SrTiO}_{3}$ buffer layer was grown on $\mathrm{HF}$-cleaned p-type $\mathrm{Si}$ (001) substrate. After the HF clean, the substrate was exposed to ultraviolet/ozone for $3 \mathrm{~min}$ to remove organic contaminants. Once in the MBE chamber, the substrate was heated to $500{ }^{\circ} \mathrm{C}$ and exposed to $\mathrm{Sr}$ flux $(2 \mathrm{~min})$ and then heated up to $780{ }^{\circ} \mathrm{C}$ in order to remove the $\mathrm{SiO}_{2}$ native oxide and form a $2 \times 1$ surface reconstruction corresponding to $1 / 2$ monolayer (ML) of Sr. Such a passivation allows the direct epitaxial growth of $\mathrm{SrTiO}_{3}$ on $\mathrm{Si}$. The $\mathrm{SrTiO}_{3}$ growth was performed at a temperature of $400{ }^{\circ} \mathrm{C}$ under a reduced oxygen partial pressure of $\mathrm{P}\left(\mathrm{O}_{2}\right)=5 \times 10^{-8}$ Torr in order to limit the oxidation of the $\mathrm{Si}$ surface. The film was then fully crystallized at $460^{\circ} \mathrm{C}$ for typically $20 \mathrm{~min}$ under ultra high vacuum. The subsequent growth of $\mathrm{BaTiO}_{3}$ was realized by co-evaporating $\mathrm{Ba}$ and $\mathrm{Ti}$ at a temperature ranging typically from $440{ }^{\circ} \mathrm{C}$ to $525^{\circ} \mathrm{C}$ and an oxygen partial pressure of typically 1 to $5 \times 10^{-7}$ Torr. The temperature, oxygen pressure, and cooling down conditions were varied to optimize the growth conditions. An oxygen plasma source could be used for post-deposition anneal of the films.

A $30 \mathrm{kV}$ reflection high-energy electron diffraction (RHEED) system was used to in situ monitor the film surface during the growth. X-ray diffraction was performed using a high-resolution four-circle smartlab diffractometer from Rigaku. $\theta-2 \theta$ and grazing incident scans were measured. The out-of-plane and in-plane lattice parameters were determined from the 002 and 200 diffraction peaks, respectively (Si 004 and 220 peak positions were used respectively as internal references). X-ray reflectometry (XRR) was performed for thickness determination. High-resolution transmission electron microscopy (HRTEM) was carried out on an aberration-corrected Hitachi HF3300S microscope (I2TEMToulouse) on cross-section samples prepared by mechanical tripod polishing. Atomic force microscope (AFM) images were recorded in tapping mode using Veeco Dimension 3100 microscope with a Nanoscope V controller. Vertical PFM was performed on an NT-MDT Ntegra AFM using single-frequency. A DC voltage of $\pm 7 \mathrm{~V}$ was applied to the sample while scanning over the surface to write domains. No top electrodes were used. The doped p-type Si substrate $\left(\sim 8 \times 10^{15} \mathrm{~cm}^{-3}\right)$ served as a back electrode. To read the written patterns, a small AC voltage was applied. The operating frequency was chosen to be close to the cantilever resonance in order to enhance the signal to noise ratio.

\section{RESULTS}

\section{A. Effect of oxygen pressure}

To study the impact of oxygen pressure on the crystalline quality, $\mathrm{BaTiO}_{3}$ films $(\sim 16-18 \mathrm{~nm})$ were prepared at $450{ }^{\circ} \mathrm{C}$ under an oxygen pressure ranging from $1 \times 10^{-7}$ to $3 \times 10^{-6}$ Torr. This set of films was slowly cooled down $\left(5^{\circ} \mathrm{C} / \mathrm{min}\right)$ under a high oxygen partial pressure $\mathrm{P}\left(\mathrm{O}_{2}\right)$ of $10^{-5}$ Torr (with a total cooling time of about $55 \mathrm{~min}$ ). As can be inferred from RHEED and AFM measurements (Fig. 1),
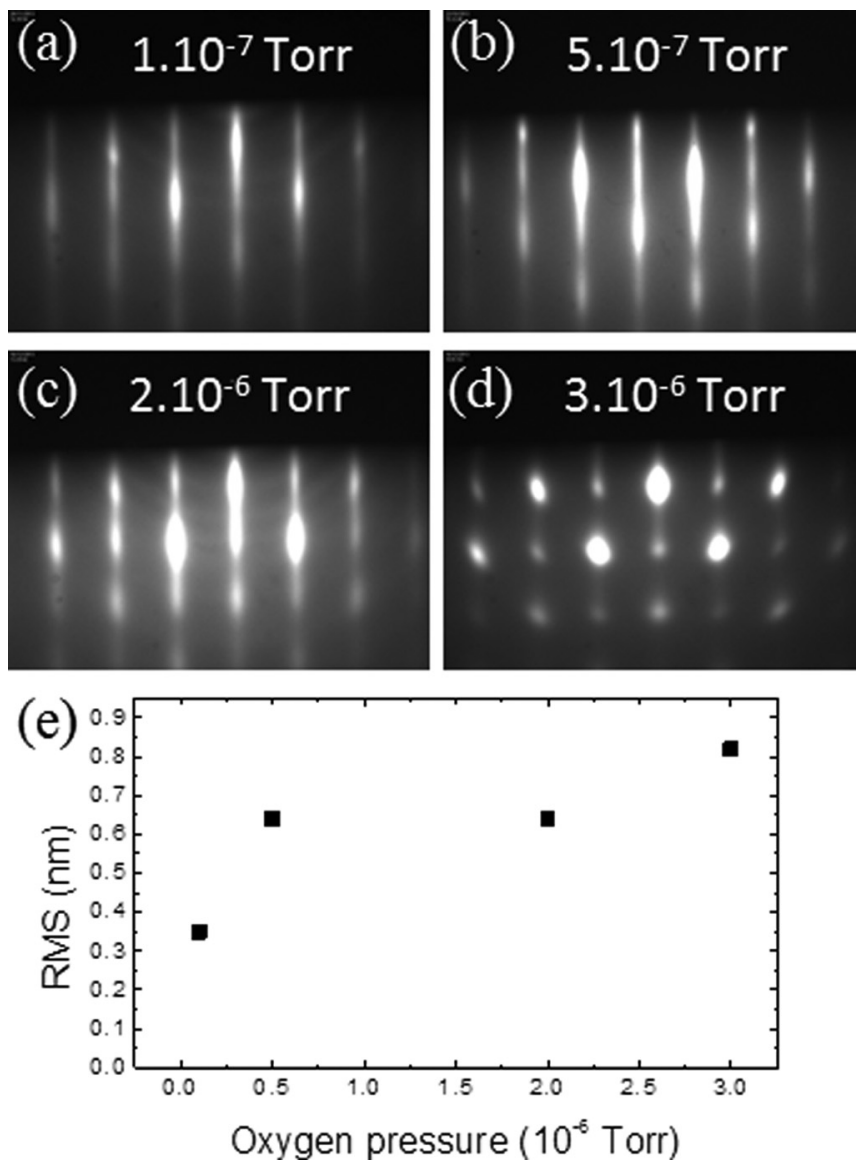

FIG. 1. (a)-(d) RHEED patterns recorded along the [100] azimuth during $\mathrm{BaTiO}_{3}$ growth at $450{ }^{\circ} \mathrm{C}$ under an oxygen pressure of (a) $1 \times 10^{-7}$ Torr, (b) $5 \times 10^{-7}$ Torr, (c) $2 \times 10^{-6}$ Torr, (d) $3 \times 10^{-6}$ Torr and (e) root mean square roughness (RMS) of the film surfaces measured by AFM as a function of oxygen pressure during $\mathrm{BaTiO}_{3}$ growth. 
the sample surface becomes rougher with increasing oxygen pressure. Until $2 \times 10^{-6}$ Torr of oxygen, the RHEED patterns present well-contrasted streaky lines indicating a flat and single-crystalline surface. Then, when the oxygen pressure gets higher, the streaky lines tend to become spotty which characterizes a rougher surface. The AFM images confirm this behavior as the root mean square roughness (RMS) increases with oxygen pressure (Fig. 1(e): RMS $=0.35 \mathrm{~nm}$ at $1 \times 10^{-7}$ Torr, RMS $=0.82 \mathrm{~nm}$ at $3 \times 10^{-6}$ Torr). The thickness of the films was determined from XRR measurements. A three-layer model was used to describe the stacks: an interfacial $\mathrm{SiO}_{2}$ layer, $\mathrm{SrTiO}_{3}$ buffer layer, and $\mathrm{BaTiO}_{3}$ layer. The density, rugosity, and thickness of each layer were left as free fitting parameters. A typical XRR scan is shown in Fig. 2(a). In this example, the density of both $\mathrm{SrTiO}_{3}$ and $\mathrm{BaTiO}_{3}$ films is found to be close to their bulk values and their roughness is $0.5 \mathrm{~nm}$. A relative density of 1.5 is found for the $\mathrm{SiO}_{2}$ layer. The thicknesses are $16.4 \mathrm{~nm}$ for $\mathrm{BaTiO}_{3}$, $4.0 \mathrm{~nm}$ for $\mathrm{SrTiO}_{3}$, and $2.7 \mathrm{~nm}$ for $\mathrm{SiO}_{2}$.

$\mathrm{X}$-ray diffraction shows that the films are single crystalline with no parasitic phase, as shown in Fig. 2(b); the epitaxial relationship between $\mathrm{BaTiO}_{3}$ and $\mathrm{Si}$ is as follows: $[110]_{\mathrm{BaTiO} 3} / /[100]_{\mathrm{Si}}$ and $(001)_{\mathrm{BaTiO}} / /(001)_{\mathrm{Si}}$ (as determined from $\phi$-scans). The intensities of the in-plane and out-ofplane diffraction peaks are weaker for the samples grown at pressures larger than $5 \times 10^{-7}$ Torr (Figs. 3(a) and 3(b)), indicating a degraded epitaxial crystalline quality. In the following, the average in-plane and out-of-plane lattice
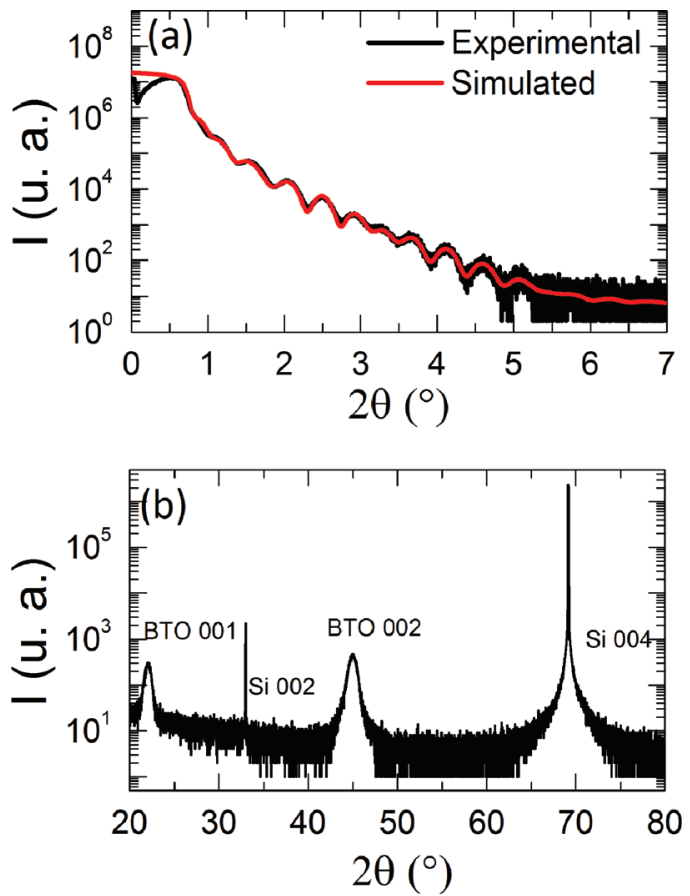

FIG. 2. (a) X-ray reflectometry scan on a $\mathrm{BaTiO}_{3} / \mathrm{SrTiO}_{3}$ stack deposited on $\mathrm{Si}$ at $450^{\circ} \mathrm{C}$ under an oxygen pressure of $1 \times 10^{-7}$ Torr. $\mathrm{A} \mathrm{SiO}_{2}$ interfacial layer is formed between $\mathrm{Si}$ and $\mathrm{SrTiO}_{3}$ during the heterostructure growth. A three-layer model was used with the interfacial $\mathrm{SiO}_{2}$ layer, $\mathrm{SrTiO}_{3}$ buffer layer, and $\mathrm{BaTiO}_{3}$ layer. The density, rugosity, and thickness of each layer were left as free fitting parameters. The density of both $\mathrm{SrTiO}_{3}$ and $\mathrm{BaTiO}_{3}$ films is found to be close to their bulk values and their roughness is $0.5 \mathrm{~nm}$. A relative density of 1.5 is found for the $\mathrm{SiO}_{2}$ layer. The thicknesses are $16.4 \mathrm{~nm}$ for $\mathrm{BaTiO}_{3}, 4.0 \mathrm{~nm}$ for $\mathrm{SrTiO}_{3}$, and $2.7 \mathrm{~nm}$ for $\mathrm{SiO}_{2}$. (b) $\theta / 2 \theta$ X-ray diffraction on a $\mathrm{BaTiO}_{3} / \mathrm{SrTiO}_{3}$ stack deposited on $\mathrm{Si}$.
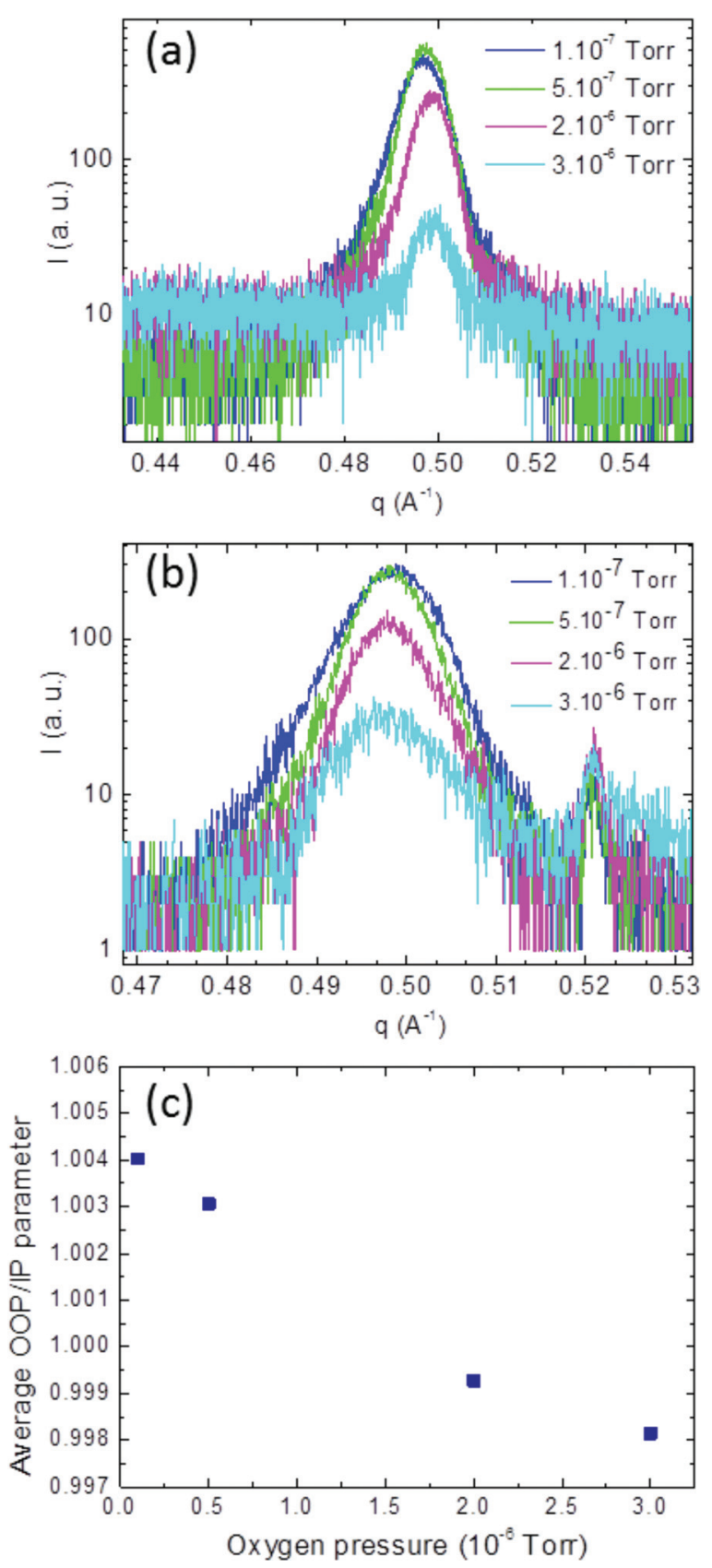

FIG. 3. X-ray diffraction scans of $\mathrm{BaTiO}_{3} / \mathrm{SrTiO}_{3}$ stack deposited on $\mathrm{Si}$ (a) $\mathrm{BaTiO}_{3} 002$ peak and (b) $\mathrm{BaTiO}_{3} 200$ peak, (c) ratio of average out-of-plane parameter/average in-plane parameter as a function of oxygen pressure during $\mathrm{BaTiO}_{3}$ growth.

parameters were determined from the maximum of the 200 and 002 diffraction peaks, respectively. Although some of the $16-18 \mathrm{~nm}$-thick films consist in a mixture of $c$ - and $a$ domains, we did not determine the individual contributions due to the limited resolution. We observe that the out-ofplane lattice parameter progressively decreases when the oxygen pressure is raised, while the in-plane parameter increases. At $5 \times 10^{-7}$ Torr, the in-plane average parameter is $4.015 \AA$ and the out-of-plane average parameter is $4.024 \AA$. These values reflect the fact that there is a mixture of $c$ - and $a$-domains. For thinner films of typically $7 \mathrm{~nm}$ grown in the same conditions, which are fully $c$-axis oriented, the lattice parameters are: $\mathrm{a}=3.996 \AA$ and 
$\mathrm{c}=4.027 \AA$. These values are close to the bulk parameters, indicating that the films are relaxed.

The ratio of the average parameters is plotted as a function of oxygen pressure in Fig. 3(c). Starting from $2 \times 10^{-6}$ Torr and above, the out-of-plane/in-plane ratio becomes lower than 1 , meaning preferentially $a$-oriented films for samples grown at high oxygen pressure, whereas below $2 \times 10^{-6}$ Torr, $\mathrm{BaTiO}_{3}$ films are mainly $c$-oriented (ratio $>1$ ). There is thus a strong effect of the oxygen pressure on the crystalline orientation of the films, which will be discussed in Sec. IV.

\section{B. Effect of temperature}

$\mathrm{BaTiO}_{3}$ films $(\sim 18-20 \mathrm{~nm})$ were grown on $\mathrm{SrTiO}_{3} / \mathrm{Si}$ under $1 \times 10^{-7}$ Torr of oxygen at different temperatures ranging from $410^{\circ} \mathrm{C}$ to $580^{\circ} \mathrm{C}$. This set of films was cooled down rapidly $\left(25^{\circ} \mathrm{C} / \mathrm{min}\right)$ under vacuum $\left(5 \times 10^{-8} \mathrm{Torr}\right)$ until $180^{\circ} \mathrm{C}$ (the total cooling time was about $10 \mathrm{~min}$ ); the temperature was then set at $180^{\circ} \mathrm{C}$ and the oxygen plasma $(400 \mathrm{~W})$ was switched on for $40 \mathrm{~min}\left(\mathrm{P}\left(\mathrm{O}_{2}\right)=1 \times 10^{-5}\right.$ Torr $)$. The RHEED patterns displayed in Figs. 4(a)-4(f) exhibit rings when the temperature exceeds $480^{\circ} \mathrm{C}$. This could denote a polycrystalline surface but all the samples, except the one grown at $580^{\circ} \mathrm{C}$, are found to be single crystalline by X-ray diffraction. Particulates are observed on the surface by AFM and additional spots are clearly seen on the RHEED patterns for films thicker than $20 \mathrm{~nm}$. Off-stoichiometry might be induced by the temperature, leading to the segregation of $\mathrm{Ba}$ on the surface. A Ba-rich-surface oxide layer has been reported for MBE-grown $\mathrm{BaTiO}_{3}$ films on $\mathrm{SrTiO}_{3}$ substrates. ${ }^{39}$ No crystalline growth happens at $580^{\circ} \mathrm{C}$. At this temperature, interface reactions occur and impede the epitaxy. At lower temperature (down to $440^{\circ} \mathrm{C}$ ), streak lines are observed and their intensity increases with temperature. At $410^{\circ} \mathrm{C}$, the lines are weak which is related to the fact that the temperature is not high enough to achieve full crystallization of $\mathrm{BaTiO}_{3}$. AFM images displayed in Figs. 4(g)-4(i) show
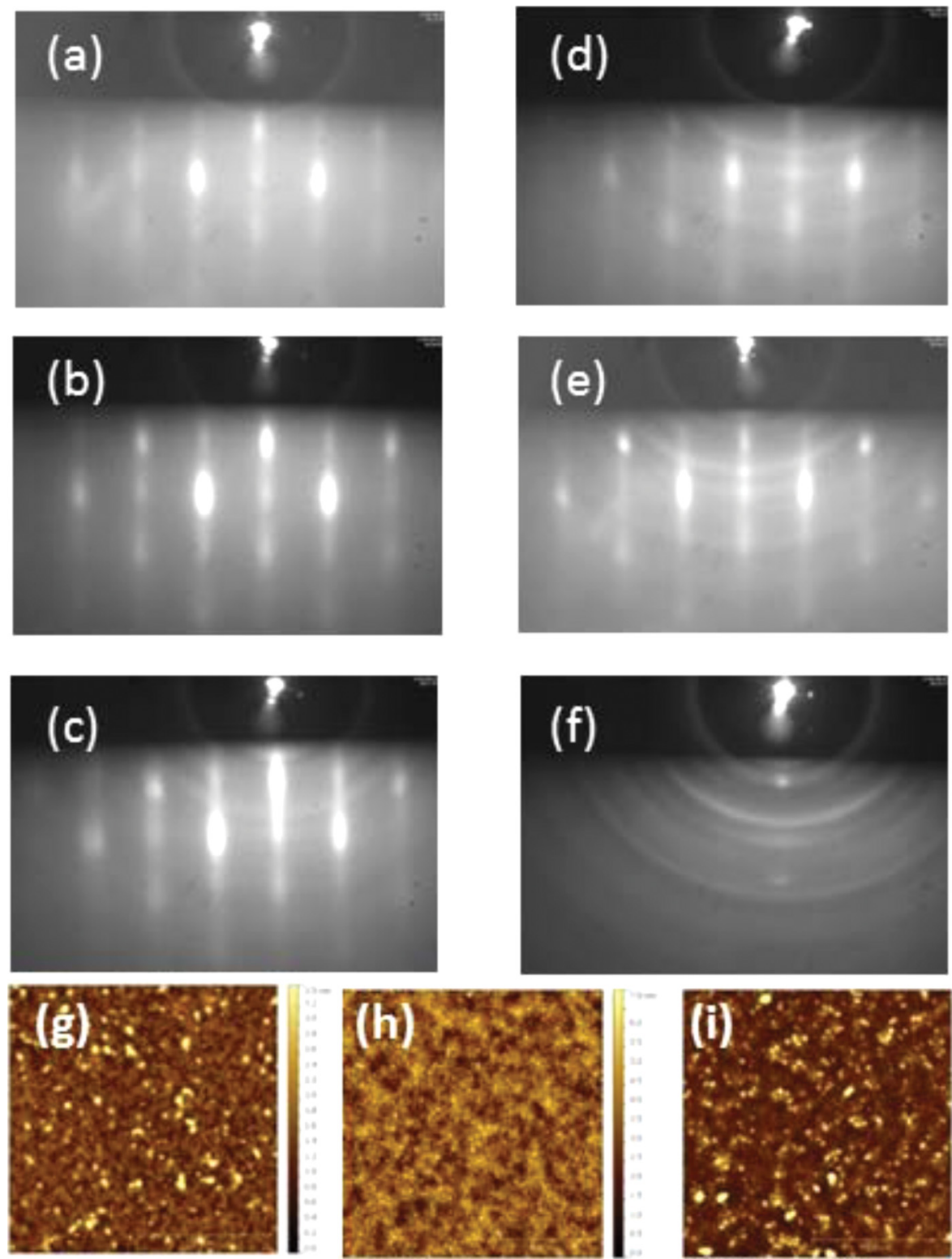

$\mathrm{RMS}=0.66 \mathrm{~nm}$

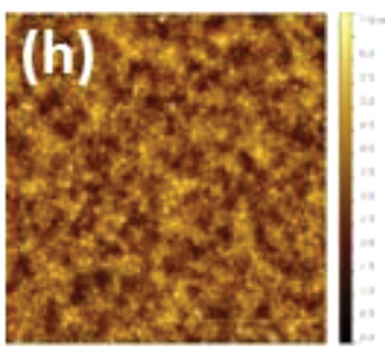

$\mathrm{RMS}=1.0 \mathrm{~nm}$

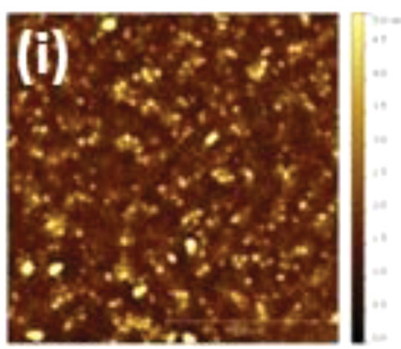

RMS $=0.83 \mathrm{~nm}$
FIG. 4. (a)-(f) RHEED patterns recorded along the [100] azimuth of $\mathrm{BaTiO}_{3}$ grown under an oxygen pressure of $1 \times 10^{-7}$ Torr at (a) $410^{\circ} \mathrm{C}$, (b) $440{ }^{\circ} \mathrm{C}$, (c) $4800^{\circ} \mathrm{C}$, (d) $500^{\circ} \mathrm{C}$, (e) $525^{\circ} \mathrm{C}$, (f) $580^{\circ} \mathrm{C}$. (g)-(i) AFM images $(1 \mu \mathrm{m} \times 1 \mu \mathrm{m})$ of the films elaborated at (g) $410^{\circ} \mathrm{C}$, (h) $480^{\circ} \mathrm{C}$, and (i) $525^{\circ} \mathrm{C}$. 


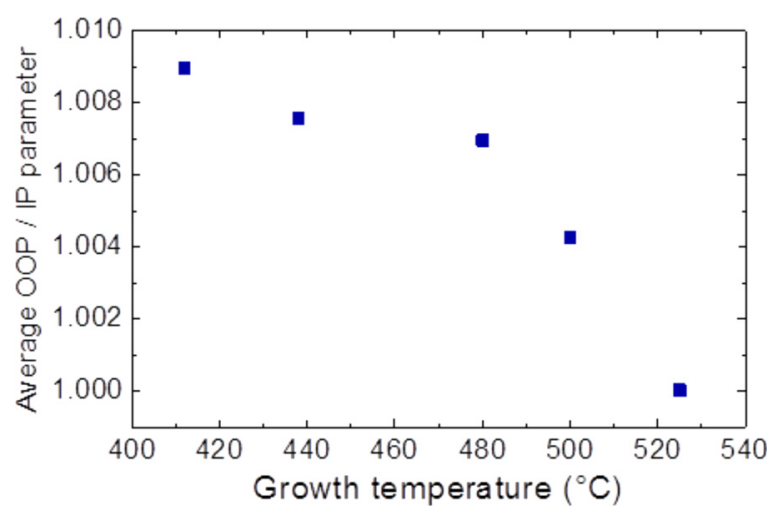

FIG. 5. Ratio of average out-of-plane parameter/average in-plane parameter as a function of growth temperature for $\mathrm{BaTiO}_{3} / \mathrm{SrTiO}_{3}$ deposited under $\mathrm{P}\left(\mathrm{O}_{2}\right)=1 \times 10^{-7}$ Torr.

homogeneous surfaces with RMS ranging from 0.7 to $1.0 \mathrm{~nm}$ for the different growth temperatures. The average out-ofplane and in-plane parameters were determined by X-ray diffraction and their ratio is plotted in Fig. 5. The $\sim 18-20 \mathrm{~nm}-$ thick films are composed of a mixture of $c$ - and $a$-axis crystallites. At $525^{\circ} \mathrm{C}$, films have similar in-plane and out-of-plane lattice parameters of 4.01-4.02 $\AA$. These values are comparable to those determined locally by geometrical phase analyses in $16 \mathrm{~nm}$ films with mixed $c$-and $a$-domains. ${ }^{13}$ As the temperature increases, we observe a decrease of the tetragonal ratio, which may indicate an increase of the $a$-axis crystallite content and/or a change in the crystalline structure parameters.

\section{Impact of growth conditions on the interface}

During the $\mathrm{SrTiO}_{3}$ and $\mathrm{BaTiO}_{3}$ growth and anneals, oxygen diffusion occurs through the film leading to the formation of an interfacial amorphous $\mathrm{SiO}_{2}$ layer between the Si substrate and the $\mathrm{SrTiO}_{3}$ buffer layer, but preserving the original epitaxial relationship. In view of integrating such materials in negative-capacitance FETs, the low permittivity interfacial layer should be suppressed. It is therefore desirable to find optimal conditions to minimize it. After the growth of $18-20 \mathrm{~nm}$-thick $\mathrm{BaTiO}_{3}$ films at $440-450{ }^{\circ} \mathrm{C}$ under $\mathrm{P}\left(\mathrm{O}_{2}\right)=1 \times 10^{-7}$ Torr, two different post-deposition processes were tested. The first one (process 1) is a slow cooling down $\left(10^{\circ} \mathrm{C} / \mathrm{min}\right)$ under high oxygen pressure $\left(1 \times 10^{-5}\right.$ Torr) and the second one (process 2$)$ is a quick cooling down $\left(25^{\circ} \mathrm{C} / \mathrm{min}\right)$ under vacuum $\left(5 \times 10^{-8} \mathrm{Torr}\right)$ followed by a plasma oxidation under $1 \times 10^{-5}$ Torr of atomic oxygen. HRTEM images shown in Figs. 6(a) and 6(b) indicate that a slow cooling down favors the formation of an amorphous $\mathrm{SiO}_{2}$ interfacial layer with an average thickness of $\sim 2.5-3.0 \mathrm{~nm}$, while a $\sim 1.0 \mathrm{~nm} \mathrm{SiO}_{2}$ thickness is observed for the other procedure (process 2). The effect of growth temperature was also investigated with $\mathrm{a} \mathrm{BaTiO}_{3}$ film grown at $525^{\circ} \mathrm{C}$ under $\mathrm{P}\left(\mathrm{O}_{2}\right)=1 \times 10^{-7}$ Torr and cooled according to process 2. As can be seen in Fig. 6(c), a thicker interfacial layer is obtained at $525^{\circ} \mathrm{C}\left(\mathrm{SiO}_{2} \sim 1.7 \mathrm{~nm}\right.$ versus $\sim 1.0 \mathrm{~nm}$ at $440^{\circ} \mathrm{C}$ ), which is expected as a higher temperature favors oxygen diffusion. In all investigated films, an abrupt interface between $\mathrm{SrTiO}_{3}$ and $\mathrm{BaTiO}_{3}$ was observed.

\section{Ferroelectricity characterization}

Ferroelectricity was investigated by vertical PFM. Three square patterns were successively written: an outer square of $7 \times 7 \mu \mathrm{m}^{2}$ was poled using a bias of $-7 \mathrm{~V}$, then a $4.5 \times 4.5 \mu \mathrm{m}^{2}$ square was poled by reversing the bias to $+7 \mathrm{~V}$, and finally an inner $2 \times 2 \mu \mathrm{m}^{2}$ pattern was poled back with $-7 \mathrm{~V}$. Hysteresis loops were recorded in spectroscopic mode $(\mathrm{Vac}=0.5 \mathrm{~V})$. We report in Fig. 7 the images and hysteresis loops obtained for a sample grown at $525^{\circ} \mathrm{C}$ and with an oxygen pressure of $1 \times 10^{-7}$ Torr. Domains are written and switched; the amplitude between opposite polarization is similar and a $180^{\circ}$ phase difference is observed. We did not observe topographic changes on the film surface. Similar images were obtained for samples grown at $450{ }^{\circ} \mathrm{C}$ with an oxygen pressure of $5 \times 10^{-7}$ Torr with mainly $c$-axis orientation. Our results are similar to previous results reported for MBE-grown $\mathrm{BaTiO}_{3}$ on $\mathrm{SrTiO}_{3}$-templated $\mathrm{Si}$ substrates. $^{13,14,40}$ The domains are stable over $24 \mathrm{~h}$ for
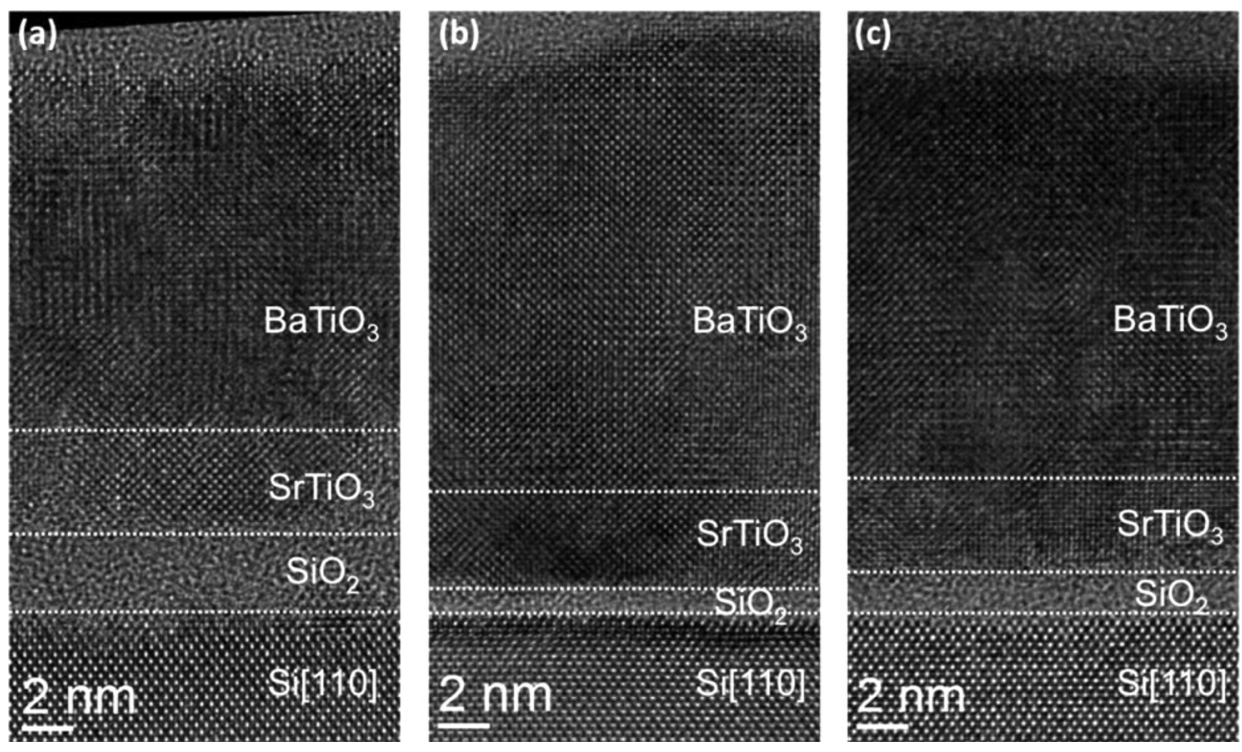

FIG. 6. High resolution transmission electron microscopy images of $\mathrm{BaTiO}_{3} / \mathrm{SrTiO}_{3}$ stacks grown under $\mathrm{P}\left(\mathrm{O}_{2}\right)=1 \times 10^{-7}$ Torr for different temperatures and post-deposition process. (a) $450^{\circ} \mathrm{C}$ - slow cooling down procedure at $\mathrm{P}\left(\mathrm{O}_{2}\right)=1 \times 10^{-5}$ Torr, (b) $440^{\circ} \mathrm{C}$-rapid cooling down under UHV followed by annealing under an oxygen plasma $\left(1 \times 10^{-5}\right.$ Torr $)$ for 40 min, (c) $525^{\circ} \mathrm{C}$-rapid cooling down under UHV followed by annealing under an oxygen plasma $\left(1 \times 10^{-5}\right.$ Torr) for $40 \mathrm{~min}$. A $\mathrm{SiO}_{2}$ interfacial layer between $\mathrm{Si}$ and $\mathrm{SrTiO}_{3}$ is formed upon $\mathrm{SrTiO}_{3}$ annealing and $\mathrm{BaTiO}_{3}$ growth and its thickness depends on the cooling down conditions. Horizontal dotted lines are only to guide the eyes. 

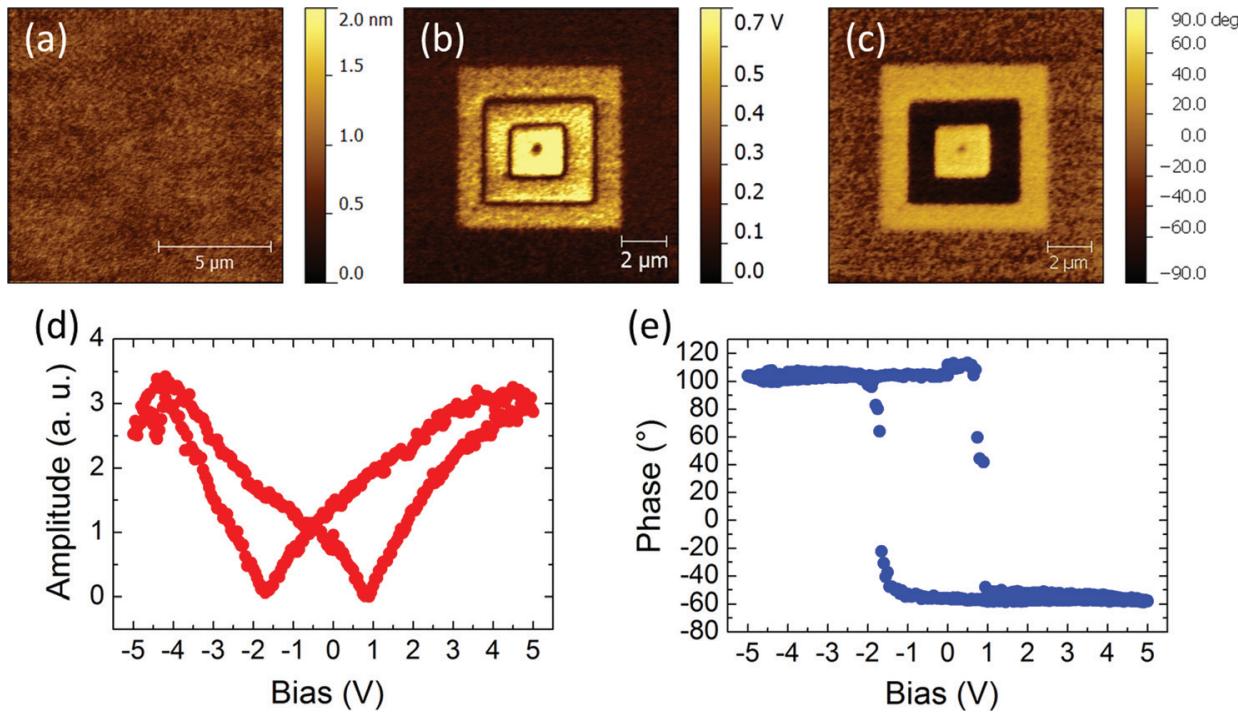

FIG. 7. (a) Topography, (b) PFM amplitude, and (c) PFM phase for a $18 \mathrm{~nm}$-thick $\mathrm{BaTiO}_{3}$ film grown at $\mathrm{P}\left(\mathrm{O}_{2}\right)=1 \times 10^{-7}$ Torr poled with $-7 \mathrm{~V} /+7 \mathrm{~V} /-7 \mathrm{~V}-$ (d) amplitude and (e) phase of PFM spectroscopy on the same stack $\left(\mathrm{V}_{\mathrm{ac}}=0.5 \mathrm{~V}\right)$. optimized films. In some cases, the contrast decreases after several hours, which can be attributed to relaxation phenomena. Domain instability might also originate from the depolarization field that is present in thin ferroelectric films on oxide or semiconductor substrates and from the fact that the domains poled by the tip might not extend throughout the film thickness. Hysteresis loops were also performed locally on the sample surface and show an abrupt hysteresis for the phase and a typical butterfly shape for the amplitude (Figs. 7(d) and 7(e)). No stable domain could be written in the mainly $a$-axis oriented films grown at oxygen pressures of $2 \times 10^{-6}$ Torr or above.

\section{DISCUSSION}

\section{A. Morphology and crystalline structure}

Both oxygen pressure and temperature are shown to strongly impact the morphology, crystalline orientation, and lattice parameters of the films. One origin may be the change in the diffusion of species at the sample surface with these two parameters, which may affect the morphology, local cationic composition, the oxygen content, and/or strain state. This could, in turn, influence the formation of the crystalline domain structure upon cooling down the sample.

We report a progressive decrease of the out-of plane lattice parameter when the oxygen pressure is raised while the in-plane parameter increases. The ratio of the out-ofplane parameter/in-plane parameter becomes lower than 1 at $2 \times 10^{-6}$ Torr, indicating that $a$-axis growth is predominant. We also observe an increase of the surface roughness with increasing oxygen pressure as shown by AFM and RHEED. The same effects have been reported for $\mathrm{BaTiO}_{3}$ films grown by laser MBE, ${ }^{24,25} \mathrm{PLD},{ }^{28,29,34-36}$ or sputtering. ${ }^{27}$ Regarding surface morphology, Zhang et al. noted a change of the topography from flat surface at $5 \times 10^{-3}$ Torr to hilly surface at 0.5 Torr for $\mathrm{BaTiO}_{3}$ films grown by PLD on $\mathrm{SrTiO}_{3}$ substrate. $^{29}$ This phenomenon was also observed by Chen et al. for films grown on $\mathrm{SrRuO}_{3} / \mathrm{SrTiO}_{3}$ : the microstructure varies from a dense large grained structure with a smooth surface to a small columnar grain structure with rough surface as the deposition pressure increases from 5 to 200 mTorr. ${ }^{36}$ To our knowledge, there is no similar study reported for $\mathrm{BaTiO}_{3}$ films grown by MBE. We explain the morphology trend with the fact that the energy of evaporated species is lower with increasing oxygen pressure because of scattering and multiple collisions between the evaporated species and oxygen molecules. Thus, the mobility of the adatoms at the surface of the substrate becomes too low to move down to lower level at the edge of islands and surface flatness is deteriorated.

The oxygen pressure also affects strongly the crystalline orientation of the films. For example, Zhao et al. observed a dependence of the crystallographic orientation on the oxygen pressure in the range of $1.5 \times 10^{-6}$ to $10^{-1}$ Torr for films grown on $\mathrm{SrTiO}_{3}$ by laser MBE. ${ }^{24}$ It is interesting to note that completely different deposition processes involving different mechanisms and energy range for the impinging species at the substrate surface show a similar trend with oxygen pressure: an increasing oxygen pressure leads to a change from $c$-axis to $a$-axis growth (although the pressure ranges are necessarily different depending on the techniques). Oxygen pressure is expected to impact the occurrence of oxygen vacancies, the cationic composition, the nature of the defects, and the resulting strain state.

Decreasing the oxygen pressure during the growth should favor the formation of oxygen vacancies $V_{\mathrm{O}}^{2+}$, which cause an increase of the $c$ lattice parameter. ${ }^{24}$ Since our films are in situ annealed at high $\mathrm{P}\left(\mathrm{O}_{2}\right)$ during cooling down, the oxygen pressure during growth should not affect the final oxygen content of the films. This point should be further investigated in our heterostructures; in particular, the impact of the oxygen pressure during $\mathrm{BaTiO}_{3}$ growth on the $\mathrm{SrTiO}_{3}$ underlying template should be explored. Indeed, it has been shown that the $\mathrm{BaTiO}_{3}$ perovskite phase could be formed by MBE from the coevaporation of metallic $\mathrm{Ba}$ and $\mathrm{Sr}$ (from effusion cells) in ultrahigh vacuum conditions, without introducing oxygen. ${ }^{41}$ Shimoyama et al. showed that oxygen was fed from the $\mathrm{SrTiO}_{3}$ substrates to the growing film surface and could evidence the incorporation of oxygen vacancies deep into the $\mathrm{SrTiO}_{3}$ substrate. ${ }^{41}$ Moreover, 
the interface between $\mathrm{BaTiO}_{3}$ film and $\mathrm{SrTiO}_{3}$ substrate remained sharp despite the amount of oxygen vacancies having moved though the interface. Recently, Rutkowski et al. reported an optical study of oxygen vacancy formation at $\mathrm{SrTiO}_{3} /(\mathrm{Ba}, \mathrm{Sr}) \mathrm{TiO}_{3}$ heterostructures grown by MBE (oxygen plasma pressure of $5 \times 10^{-7}$ Torr). ${ }^{26}$ They showed that defects accumulate at the interface and that this accumulation depends on the growth conditions, particularly $\mathrm{P}\left(\mathrm{O}_{2}\right)$. It is therefore possible that oxygen from the $\mathrm{SrTiO}_{3}$ template moves towards the $\mathrm{BaTiO}_{3}$ film surface during the growth of our heterostructures. Defects in the $\mathrm{BaTiO}_{3}$ film have also been shown to depend on the oxygen pressure. Zhu et $a{ }^{25}$ observed a change in the type of predominant defects in laser-MBE grown $\mathrm{BaTiO}_{3}$ on $\mathrm{SrTiO}_{3}$ by varying the oxygen pressure in the range of $1.5 \times 10^{-7}$ to $1.5 \times 10^{-4}$ Torr: with the lowering of oxygen pressure, the major defects in the films change from threading dislocations into (111) nanotwins. Advanced TEM studies will be performed to determine whether the underlying $\mathrm{SrTiO}_{3}$ template as well as the $\mathrm{BaTiO}_{3}$ film exhibit a different defect structure depending on the $\mathrm{P}\left(\mathrm{O}_{2}\right)$ conditions.

Another strong impact of the oxygen pressure during $\mathrm{BaTiO}_{3}$ growth is a possible change in the cationic ratio $\mathrm{Ti} / \mathrm{Ba}$, which has been reported for PLD-grown films. ${ }^{30,32,36}$ Chen et al. reported an increasing $\mathrm{Ti} / \mathrm{Ba}$ ratio with increasing oxygen pressure for films on $\mathrm{SrTiO}_{3}$ substrates: ${ }^{36}$ the films change from Ti-deficient to Ti-rich with increasing the oxygen pressure. We can suspect that compositional changes occur in our films with $\mathrm{P}\left(\mathrm{O}_{2}\right)$ (this point will be investigated in the future by EELS/EDX in a transmission electron microscope). In addition to changing the diffusion of the species on the substrate's surface, an additional effect may arise from oxygen pressure in MBE. Although MBE should enable a straightforward control of the composition due to the independent control of each metal source, the presence of oxygen in the chamber makes such a control challenging. Indeed, oxygen induces surface oxidation of the hot metal charges in the effusion cells as well as oxidation of the evaporated species. As a result, the oxygen pressure used during the film growth may modify the stoichiometry.

We also think that the crystalline changes we observed with increasing the growth temperature are related to cationic modifications.

Change in the cationic ratio is expected to modify the lattice parameter of the films. Off stoichiometries will indeed lead to structural buckling and defects. In a detailed study of the MBE growth of $\mathrm{LaCrO}_{3}$, it was shown that the crystalline quality, film surface morphology, and defect density are sensitive to the La-to- $\mathrm{Cr}$ cationic ratio. ${ }^{42}$ Many perovskite oxides can accommodate cationic composition deviation while keeping a perovskite structure; the physical properties are, however, strongly impacted..$^{39,42-45}$ We did not observe change in the RHEED patterns for the different films. However, \% level change in the cationic ratio cannot be precluded. In Ref. 39, it is reported that changes in composition of at least $\pm 20 \%$ are needed to observe noticeable changes in the $\mathrm{BaTiO}_{3}$ RHEED patterns for films deposited on bulk $\mathrm{SrTiO}_{3}$ substrates. The control of the cationic composition during the growth process remains one of the major challenges for the molecular beam epitaxy of complex oxides.

Finally, regarding oxygen pressure, one should note that the working conditions reported in the literature for the epitaxial growth of $\mathrm{BaTiO}_{3}$ on $\mathrm{SrTiO}_{3}$-buffered $\mathrm{Si}$ by MBE span an extremely large range, of about three orders of magnitude: $4-5 \times 10^{-8}$ Torr of molecular oxygen in Ref. 7,1 to $5 \times 10^{-7}$ Torr of molecular oxygen in this work, $5 \times 10^{-6}$ Torr of molecular oxygen in Ref. 13 , and $3 \times 10^{-5}$ Torr under rf oxygen plasma in Ref. 4. It is not yet understood why different equipments/processes result in such a difference in the optimal oxygen pressure.

\section{B. Ferroelectricity}

Ferroelectricity in epitaxial $\mathrm{BaTiO}_{3}$ deposited on silicon without a conducting bottom electrode cannot be evidenced by conventional $\mathrm{C}-\mathrm{V}$ electrical measurements. Indeed, in such capacitive structures, the voltage applied across the heterostructure is mainly dropped in the low permittivity interfacial $\mathrm{SiO}_{2}$ layer (of typically 20-30 $\mathrm{A}$ ). Moreover, the silicon in depletion also contributes to the total capacitance. Hence, it is not possible to reach an effective electrical field that can switch the ferroelectric layer. Probes in which the electrical field applied locally is large enough to switch the ferroelectric are required to assert ferroelectricity.

For our optimized films with mainly $c$-axis orientation or grown at higher temperature $\left(525^{\circ} \mathrm{C}\right)$, we observe stable domain written by PFM and hysteresis loops, that are typical for ferroelectric materials. Since few years, it has been pointed out that ionic and electrochemical phenomena may play a major role in scanning probe microscopy. ${ }^{46}$ It has been shown that domain writing/switching as well as hysteresis loops can be obtained in non-ferroelectric compounds such as crystalline $\mathrm{LaAlO}_{3} / \mathrm{SrTiO}_{3}$ heterostructures, ${ }^{47}$ amorphous $\mathrm{LaAlO}_{3}$ (Ref. 48), or transition metal oxides involved in memristive devices like $\mathrm{TiO}_{2}$ or $\mathrm{SrTiO}_{3} .{ }^{49}$ Oxygen vacancies may play a major role in the electromechanical response. In epitaxial $\mathrm{LaAlO}_{3} / \mathrm{SrTiO}_{3}$ heterostructures, it was suggested that the oxygen vacancy distribution throughout the $\mathrm{LaAlO}_{3}$ thickness is reversibly modified, leading to the switchable electromechanical response. In this system, the PFM signal of the written domain is found to decay in tens of minutes. Stable domains were written in amorphous $3 \mathrm{~nm} \mathrm{LaAlO}_{3}$ films deposited on $\mathrm{Si}$ by MBE. ${ }^{48}$ However, in this study, the $\mathrm{LaAlO}_{3}$ film was deposited from the evaporation of a $\mathrm{LaAlO}_{3}$ pellet without additional oxygen pressure in the first stage of the growth $(\sim 1 \mathrm{~nm})$ in order to limit interface reactions with $\mathrm{Si}$, which promotes a high density of oxygen vacancies in the film. In our study, oxygen is provided throughout the whole growth process of the $\mathrm{SrTiO}_{3} /$ $\mathrm{BaTiO}_{3}$ heterostructure; moreover, the films were annealed in situ after deposition under oxygen. We thus exclude that the main contribution to the electromechanical response is related to oxygen vacancies in our films. The PFM results, together with the crystalline characterization ( $c$-axis oriented tetragonal $\mathrm{BaTiO}_{3}$ phase), show that the $\mathrm{BaTiO}_{3}$ films are ferroelectric with a polarization that can be switched between up/down states. 


\section{CONCLUSION}

In this work, different deposition conditions were investigated to optimize the epitaxial $c$-axis growth of 16-20 nm-thick tetragonal $\mathrm{BaTiO}_{3}$ films on silicon by MBE. Low oxygen pressures (in the range of $1 \times 10^{-7}$ to $5 \times 10^{-7}$ Torr) are favorable for an out-of-plane $c$-axis growth together with smooth films and high epitaxial crystalline quality. A limited window is available for the growth temperature $\left(440-525^{\circ} \mathrm{C}\right)$ of $\mathrm{BaTiO}_{3}$ in these $\mathrm{MBE}$ conditions. Although a high crystalline quality of this refractory material requires a high temperature, a compromise has to be found with interfacial reactivity. Lower temperatures $\left(\sim 450^{\circ} \mathrm{C}\right)$ and quick cooling down with a post-deposition oxygen plasma anneal are also prone to limit the regrowth of the unfavorable low permittivity $\mathrm{SiO}_{2}$ layer at the $\mathrm{Si} / \mathrm{SrTiO}_{3}$ interface. A challenging aspect of the epitaxial growth of $\mathrm{BaTiO}_{3}$ by $\mathrm{MBE}$ is the control of the cationic composition in the first stages of the growth, which may be affected by the processing conditions (such as oxygen pressure and temperature) and the control of its stability with time. Finally, the ferroelectricity of $16-20 \mathrm{~nm}$ thick films was evidenced by PFM measurements coupled to the structural characterization showing $c$-axis oriented tetragonal crystalline structure. The critical thickness allowing ferroelectricity to be stabilized on such $\mathrm{SrTiO}_{3}-\mathrm{Si}$ substrates will be investigated, which is relevant for integrating such ferroelectric films in field-effect devices.

\section{ACKNOWLEDGMENTS}

The authors acknowledge support from the Institute of Multiscale Science and Technology (Labex iMUST) supported by the French Agence Nationale de la Recherche (ANR). They also acknowledge P. Regreny, C. Botella, and J. B. Goure for technical assistance at INL.

${ }^{1}$ S. Salahuddin and S. Datta, Nano Lett. 8, 405 (2008).

${ }^{2}$ D. J. Frank, P. M. Solomon, C. Dubourdieu, M. M. Frank, V. Narayanan, and T. N. Theis, IEEE Trans. Electron. Devices 61, 2145 (2014).

${ }^{3}$ C. Xiong, W. H. P. Pernice, J. H. Ngai, J. W. Rainer, D. Kumah, F. J. Walker, C. H. Ahn, and H. X. Tang, Nano Lett. 14, 1419 (2014).

${ }^{4}$ S. Abel, T. Stöferle, C. Marchiori, C. Rossel, M. D. Rossell, R. Erni, D. Caimi, M. Sousa, A. Chelnokov, B. J. Offrein, and J. Fompeyrine, Nat. Commun. 4, 1671 (2013).

${ }^{5}$ R. A. Mc Kee, F. J. Walker, and M. F. Chisholm, Phys. Rev. Lett. 81, 3014 (1998).

${ }^{6}$ J. W. Reiner, A. M. Kolpak, Y. Segal, K. F. Garrity, S. Ismail-Beigi, C. H. Ahn, and F. J. Walker, Adv. Mater. 22, 2919 (2010).

${ }^{7}$ V. Vaithynathan, J. Lettieri, W. Tian, A. Sharan, A. Vasudevarao, Y. L. Li, A. Kochhar, H. Ma, J. Levy, P. Zschack, J. C. Woicik, L. Q. Chen, V. Gopalan, and D. G. Schlom, J. Appl. Phys. 100, 024108 (2006).

${ }^{8}$ F. Niu and B. W. Wessels, J. Vac. Sci. Technol., B 25, 1053 (2007).

${ }^{9}$ J. W. Park, D. F. Bogorin, C. Cen, D. A. Felker, Y. Zhang, C. T. Nelson, C. W. Bark, C. M. Folkman, X. Q. Pan, M. S. Rzchowski, J. Levy, and C. B. Eom, Nat. Commun. 1, 94 (2010).

${ }^{10}$ C. Dubourdieu, I. Gélard, O. Salicio, G. Saint-Girons, B. Vilquin, and G. Hollinger, Int. J. Nanotechnol. 7(4-8), 320 (2010).

${ }^{11}$ G. Niu, S. Yin, G. Saint-Girons, B. Gautier, P. Lecoeur, V. Pillard, G. Hollinger, and B. Vilquin, Microelectron. Eng. 88, 1232 (2011).

${ }^{12}$ S. H. Baek, J. Park, D. M. Kim, V. A. Aksyuk, R. R. Das, S. D. Bu, D. A. Felker, J. Lettieri, V. Vaithyanathan, S. S. N. Bharadwaja, N. BassiriGharb, Y. B. Chen, H. P. Sun, C. M. Folkman, H. W. Jang, D. J. Kreft, S. K. Streiffer, R. Ramesh, X. Q. Pan, S. Trolier-McKinstry, D. G. Schlom, M. S. Rzchowski, R. H. Blick, and C. B. Eom, Science 334, 958 (2011).
${ }^{13}$ C. Dubourdieu, J. Bruley, T. M. Arruda, A. Posadas, J. Jordan-Sweet, M. M. Frank, E. Cartier, D. J. Frank, S. V. Kalinin, A. A. Demkov, and V. Narayanan, Nat. Nanotechnol. 8, 748 (2013).

${ }^{14}$ R. Droopad, R. Contreras-Guerrero, J. P. Veazey, Q. Qiao, R. F. Klie, and J. Levy, Microelectron. Eng. 109, 290 (2013).

${ }^{15}$ L. Louahadj, D. Le Bourdais, L. Largeau, G. Agnus, L. Mazet, R. Bachelet, P. Regreny, D. Albertini, V. Pillard, C. Dubourdieu, B. Gautier, $\mathrm{P}$. Lecoeur, and G. Saint-Girons, "Ferroelectric $\mathrm{Pb}(\mathrm{Zr}, \mathrm{Ti}) \mathrm{O}_{3}$ epitaxial layers on GaAs," Appl. Phys. Lett. 103, 212901 (2013).

${ }^{16}$ L. Louahadj, R. Bachelet, P. Regreny, L. Largeau, C. Dubourdieu, and G. Saint-Girons, Thin Solid Films 563, 2 (2014).

${ }^{17}$ H. Colder, B. Domenges, C. Jorel, P. Marie, M. Boisserie, S. Guillon, L. Nicu, A. Galdi, and L. Méchin, J. Appl. Phys. 115(5), 053506 (2014).

${ }^{18}$ A. I. Khan, D. Bhowmik, P. Yu, S. J. Kim, X. Pan, R. Ramesh, and S. Salahuddin, Appl. Phys. Lett. 99, 113501 (2011).

${ }^{19}$ D. J. R. Appleby, N. K. Ponon, K. S. K. Kwa, B. Zou, P. K. Petrov, T. Wang, N. M. Alford, and A. O'Neill, Nano Lett. 14, 3864 (2014).

${ }^{20}$ R. Droopad, Z. Yu, H. Li, Y. Liang, C. Overgaard, A. Demkov, X. Zhang, K. Moore, K. Eisenbeiser, M. Hu, J. Curless, and J. Finder, J. Cryst. Growth 251, 638 (2003).

${ }^{21}$ H. Li, X. Hu, Y. Wei, Z. Yu, X. Zhang, R. Droopad, A. A. Demkov, J. Edwards, Jr., K. Moore, W. Ooms, J. Kulik, and P. Fejes, Appl. Phys. 93, 4521 (2003)

${ }^{22}$ G. Niu, G. Saint-Girons, B. Vilquin, G. Delhaye, J.-L. Maurice, C. Botella, Y. Robach, and G. Hollinger, Appl. Phys. Lett. 95, 062902 (2009).

${ }^{23}$ M. Choi, A. Posadas, R. Dargis, C.-K. Shih, A. A. Demkov, D. H. Triyoso, N. D. Theodore, C. Dubourdieu, J. Bruley, and J. Jordan-Sweet, J. Appl. Phys. 111, 064112 (2012).

${ }^{24}$ T. Zhao, F. Chen, H. Lu, G. Yang, and Z. Chen, J. Appl. Phys. 87, 7442 (2000).

${ }^{25}$ Y. L. Zhu, S. J. Zheng, D. Chen, and X. L. Ma, Thin Solid Films 518, 3669 (2010).

${ }^{26}$ M. M. Rutkowski, K. McNicholas, Z. Q. Zeng, F. Tuomisto, and L. J. Brillson, J. Phys. D: Appl. Phys. 47, 255303 (2014).

${ }^{27}$ N. Y. Lee, T. Sekine, Y. Ito, and K. Uchino, Jpn. J. Appl. Phys., Part 133 , 1484 (1994).

${ }^{28}$ J. Zhang, D. Cui, Y. Zhou, L. Li, Z. Chen, M. Szabadi, and P. Hess, Thin Solid Films 287, 101 (1996).

${ }^{29}$ J. Zhang, D. Cui, H. Lu, Z. Chen, Y. Zhou, L. Li, G. Yang, S. Martin, and P. Hess, Jpn. J. Appl. Phys., Part 1 36, 276 (1997).

${ }^{30}$ J. Gonzalo, R. G. San Roman, J. Perriere, C. N. Afonso, and R. P. Casero, Appl. Phys. A 66, 487 (1998).

${ }^{31}$ C. L. Li, D. Cui, Y. Zhou, H. Lu, Z. Chen, D. Zhang, and F. Wu, Appl. Surf. Sci. 136, 173 (1998).

${ }^{32}$ C. L. Li, Z. H. Chen, Y. L. Zhou, and D. F. Cui, J. Phys.: Condens. Matter 13, 5261 (2001).

${ }^{33}$ S. B. Mi, C. L. Jia, T. Hegg, O. Trihaveesak, J. Schubert, and K. Urban, J. Cryst. Growth 283, 425 (2005).

${ }^{34}$ J. Hiltunen, D. Seneviratne, R. Sun, M. Stolfi, H. L. Tuller, J. Lappalainen, and V. Lantto, J. Electroceram. 22, 416 (2009).

${ }^{35}$ J. Hiltunen, D. Seneviratne, H. L. Tuller, J. Lappalainen, and V. Lantto, J. Electroceram. 22, 395 (2009).

${ }^{36}$ A. P. Chen, F. Khatkhatay, W. Zhang, C. Jacob, L. Jiao, and H. Wang, J. Appl. Phys. 114, 124101 (2013).

${ }^{37}$ C. Wang, B. L. Cheng, S. Y. Wang, H. B. Lu, Y. L. Zhou, Z. H. Chen, and G. Z. Yang, Thin Solid Films 485, 82 (2005).

${ }^{38}$ T. Delage, C. Champeaux, A. Catherinot, J. F. Seaux, V. Madrangeas, and D. Cros, Thin Solid Films 453-454, 279 (2004).

${ }^{39}$ A. Barbier, C. Mocuta, D. Stanescu, P. Jegou, N. Jedrecy, and H. Magnan, J. Appl. Phys. 112, 114116 (2012).

${ }^{40}$ S. Abel, M. Sousa, C. Rossel, D. Caimi, M. D. Rossell, R. Erni, J. Fompeyrine, and C. Marchiori, Nanotechnology 24, 285701 (2013).

${ }^{41}$ K. Shimoyama, M. Kiyohara, K. Kubo, A. Uedono, and K. Yamabe, J. Appl. Phys. 92, 4625 (2002).

${ }^{42}$ L. Qiao, K. H. L. Zhang, M. E. Bowden, T. Varga, V. Shutthanandan, R. Colby, Y. Du, B. Kabius, P. V. Sushko, M. D. Biegalski, and S. A. Chambers, Adv. Funct. Mater. 23, 2953 (2013).

${ }^{43}$ I. Gélard, N. Jehanathan, H. Roussel, S. Gariglio, O. I. Lebedev, G. Van Tendeloo, and C. Dubourdieu, Chem. Mater. 23, 1232 (2011).

${ }^{44}$ A. A. Bosak, O. Yu. Gorbenko, A. R. Kaul, I. E. Graboy, C. Dubourdieu, J.-P. Sénateur, and H. W. Zandbergen, J. Magn. Magn. Mater. 211, 61 (2000). 
${ }^{45}$ C. Dubourdieu, M. Audier, J. P. Sénateur, and J. Pierre, J. Appl. Phys. 86(12), 6945 (1999).

${ }^{46}$ S. V. Kalinin, S. Jesse, A. Tselev, A. P. Baddorf, and N. Balke, ACS Nano 5, 5683 (2011).

${ }^{47}$ C. W. Bark, P. Sharma, Y. Wang, S. H. Baek, S. Lee, S. Ryu, C. M. Folkman, T. R. Paudel, A. Kumar, S. V. Kalinin, A. Sokolov, E. Y.
Tsymbal, M. S. Rzchowski, A. Gruverman, and C. B. Eom, Nano Lett. 12, 1765 (2012).

${ }^{48}$ A. S. Borowiak, N. Baboux, D. Albertini, B. Vilquin, G. Saint-Girons, S. Pelloquin, and B. Gautier, Appl. Phys. Lett. 105, 012906 (2014).

${ }^{49}$ Y. Kim, A. N. Morozovska, A. Kumar, S. Jesse, E. A. Eliseev, F. Alibart, D. Strukov, and S. V. Kalinin, ACS Nano 6, 7026 (2012). 